\title{
The effects of strength training on cognitive performance in elderly women
}

\author{
This article was published in the following Dove Press journal: \\ Clinical Interventions in Aging \\ I June 2016 \\ Number of times this article has been viewed
}

\author{
André de Camargo \\ Smolarek ${ }^{1,2}$ \\ Luis Henrique Boiko \\ Ferreira $^{1,2}$ \\ Luis Paulo Gomes \\ Mascarenhas' \\ Steven R McAnulty ${ }^{3}$ \\ Karla Daniele Varela ${ }^{4}$ \\ Mônica C Dangui ${ }^{4}$ \\ Marcelo Paes de Barros ${ }^{5}$ \\ Alan C Utter ${ }^{3}$ \\ Tácito P Souza-Junior ${ }^{2,3}$ \\ 'Department of Physical Education, \\ Biochemistry of the Exercise \\ Laboratory, Centro Oeste University \\ State, Irati, Parana, ${ }^{2}$ Research \\ Group on Metabolism, Nutrition \\ and Strength Training, Department \\ of Physical Education, Federal \\ University of Parana, Curitiba, Brazil; \\ ${ }^{3}$ Department of Health and Exercise \\ Science, Appalachian State University, \\ Boone, NC, USA; ${ }^{4}$ Physical Education \\ Department, Faculty Guairaca, \\ Guarapuava, Parana, ${ }^{5}$ Institute of \\ Physical Activity and Sports Science \\ (ICAFE), Cruzeiro do Sul University, \\ São Paulo, Brazil
}

Correspondence: André de Camargo Smolarek

Department of Physical Education, Biochemistry of the Exercise Laboratory, Universidade Estadual do Centro Oeste, PR I 53 KM 7, Bairro Riozinho, Irati, Paraná, Brazil

Tel +55 4299443213

Email andrecsk@gmail.com

\begin{abstract}
Aging is a degenerative process marked by recognized functional, physiological, and metabolic impairments, such as dynapenia and diminished cognitive capacity. Therefore, the search for innovative strategies to prevent/delay these physiological and cognitive disorders is essential to guarantee the independence and life quality of an elderly population. The aim of this work is to verify the effect of a 12 -week resistance exercise program on the general physical aptitude and cognitive capacities of elderly and sedentary women. Twenty-nine women ( $65.87 \pm 5.69$ years) were divided into two groups. The control group was composed of eight elderly women who met the same inclusion criteria of the study and the strength training group was composed of 29 elderly women who were subjected to a resistance exercise program defined by 12 upper and lower limb exercises combined in $3 \times 10$ repetitions with 1-minute interval between repetitions and two resting minutes between exercises (three times/ week). Weight loads were fixed between $60 \%$ and $75 \%$ of the apparent 1 repetition maximum, which was estimated by the test of 10 maximum repetitions. The direct curl was performed for upper body strength evaluation with $2.3 \mathrm{~kg}$ dumbbells for 30 seconds, whereas the chair test was used for lower body evaluation (total sit-stand movements in 30 seconds). The cognitive capacities of subjects were evaluated by "The Montreal Cognitive Assessment" questionnaire. After 12 weeks, the elderly group showed significant increases in the average upper body strength (58\%), lower body strength (68\%), and cognitive capacity $(19 \%)$. The present study demonstrated that regular resistance exercises could provide significant gains on the upper and lower body strength concomitant to positive improvements on cognitive capacities of elderly women, bringing enhanced life quality.
\end{abstract}

Keywords: aging, life quality, cognition, resistance training

\section{Introduction}

A bulk of data have shown that aging is strongly marked by neurodegenerative processes that cause substantial loss of sensory, auditory, and vision functions and decreases in motor control associated with poor life quality of the elderly population worldwide. ${ }^{1}$ Interestingly, the prescription of strength exercises as well as the adherence to such exercise programs is also dependent on the severity of sensorial aging. ${ }^{2-5}$

Research indicates that older people doing strength training have many benefits, especially in aspects reflecting their daily lives, including work, skills, and autonomy. ${ }^{6}$ In agreement, Kirk-Sanchez and McGough ${ }^{7}$ investigated the link between regular physical activity and physiological/metabolic pathways involved in cerebral allostasis, neuroprotective benefits, and cognitive capacities in aged subjects. ${ }^{8-10}$ Rheological alterations in blood, augmentation of oxygen uptake, inhibition of vascular inflammatory processes, and improvement of antioxidant defenses culminating in enhanced redox status in muscle and neuronal tissues can be considered one of the proposed mechanisms. ${ }^{11}$ 
Strength exercises are very suitable for elderly populations but the benefits that go beyond strength gain are poorly described. Little research has been conducted regarding the mechanisms required in strength training that can affect cognitive performance. Therefore, the aim of this study is to investigate the effect of 12 weeks of strength training in anthropometric and general physical fitness indexes and cognition capacities of elderly women.

\section{Materials and methods Subjects}

Fifty-three elderly women ( $65.87 \pm 5.69$ years) who took part in the social-entertaining activities at the Faculty Guairaca (Guarapuava, Brazil) were randomly recruited for the study. From the initial screening of 53 volunteers, only 37 met the inclusion criteria of age, weekly time availability, willingness to participate in a supervised exercise program, and not exhibiting any Alzheimer's symptoms or any other neurodegenerative disease previously diagnosed by a doctor. Moreover, no previous experience in strength training was also included as a selection criterion in order to emphasize the beneficial effects of the resistance exercises (based on our selected parameters). After a random draw was performed, eight of 37 women were assigned to the control group and 29 women were assigned to the strength training group. The control group was instructed to maintain the same routine, without changing the amount of exercise time and daily diet until the end of the intervention. All the experimental protocols described here were approved by the ethics committee of the University of Contestado (PR, Brazil; protocol number: 03763312.7.0000.0117) in agreement with the guidelines of the Helsinki protocol. All participants provided written informed consent and this trial was registered with NCT number: 001/2014.

\section{Strength training program}

The strength training group repeated the described protocol three times a week on alternate days. The strength training group followed a 12-week strength exercise program that involved both resistance machines and dumbbells. Five exercises were used for lower body (adductor, abductor, extensor machine, flexor machine, and horizontal leg press) and five exercises for upper body (front pull downs, peck-deck, triceps pulley, alternating biceps, and shoulder lateral raise).

The exercise program prioritized major muscle groups and specific movements that were also required in the aforementioned fitness component evaluation. In order to estimate the load volume, the experimental group was subjected to the 10 repetition maximum (RM) test, which was accordingly used to estimate the $1 \mathrm{RM}$ value. ${ }^{12}$ We avoided performing the $1 \mathrm{RM}$ test directly since our experimental group was composed of inexperienced elderly women, which might increase their risk of injuries. Once $10 \mathrm{RM}$ and $1 \mathrm{RM}$ were determined, we fixed the appropriate load of strength exercises to $60 \%-70 \%$ of apparent 1 RM..$^{13,14}$ Three sets of ten repetitions with 1-minute interval between sets for each exercise were performed. ${ }^{15}$

\section{Anthropometric parameters}

A digital scale Filizola ${ }^{\circledR}$ with a capacity of $200 \mathrm{~kg}$ and resolution of $100 \mathrm{~g}$ was used for weighing. Subjects were instructed to attend the first evaluation clothed in shorts and t-shirt. ${ }^{16}$ A stadiometer Gofeka/Cardiomed ${ }^{\circledR}$ with a capacity of $220 \mathrm{~cm}$ and $0.1 \mathrm{~mm}$ resolution was employed for measuring the height of the subjects who were evaluated barefooted, with the head in the Frankfurt plane. ${ }^{16}$

According to the standards of the International Society for the Advancement of Kinanthropometry, the body mass index was calculated by the ratio (body mass) $/\left(\right.$ height) ${ }^{2}$, expressed as $\mathrm{kg} / \mathrm{m}^{2}$ with body weight measured using a regular scale (Welmy ${ }^{\mathrm{TM}}$ ) and height obtained using a wall-fixed stadiometer (Sanny ${ }^{\mathrm{TM}}$ ). Waist circumference was defined as the narrowest point between the lower costal border and the superior border of the iliac crest. Waist circumference measurement was taken twice to the nearest $0.1 \mathrm{~cm}$ and the average was used for analysis. ${ }^{17}$

\section{Fitness component evaluation}

All fitness evaluations were performed pre/post the strength training intervention program by the same examiner and at the same time of day (between 8 and 9 am). Variables for the fitness evaluation were selected based on criteria that minimized risks to participants, costs (thereby, selecting the more economically viable measurements), and responsiveness to strength exercises.

Flexibility was evaluated by the "sit-and-reach" test. This test involved sitting on the floor with legs stretched out straight ahead. The soles of the feet were placed flat against the box and one knee was locked and pressed flat to the floor (the tester assisted by holding one knee down when necessary). With the palms together facing downwards, the subject reached forward along the measuring line as far as possible. The score was recorded in centimeters short of reaching the toe (minus score) or beyond it (plus score). Two trials with each leg were performed and the best value of each leg was registered. The average of both legs was recorded. ${ }^{18}$

Upper limb strength (ULS) was evaluated by the maximum repetitions number of arm curl, executed with a 
$2.3 \mathrm{~kg}$ dumbbell in 30 seconds. ${ }^{18}$ The lower limb strength (LLS) was evaluated using the chair test, where the elderly women must sit down and stand as many times as possible in 30 seconds. ${ }^{18}$ All tests were performed in the laboratory of Faculty Guairaca with two experienced evaluators to ensure the safety of assessment and data quality.

\section{Cognitive capacity test}

Volunteer's cognitive capacities were assessed by "The Montreal Cognitive Assessment" questionnaire, well known as the "MoCA" test. The MoCA test checks the current clinical status of cognitive performance and had Portuguese adaptation where women under 26 points were classified with cognitive disturbance. ${ }^{19-22}$

\section{Statistical analysis}

All data were presented as mean \pm standard deviation. A Shapiro-Wilks test for normality was used. The (twoway) analysis of variance with Tukey's post hoc was used to verify the significance of pre/post strength training program on flexibility, ULS, LLS, and MoCA. The relationship between fitness component indexes and cognitive capacities (MoCA) was assessed by a binary logistic regression with a significance level at $P \leq 0.05$ with $95 \%$ confidence interval. All tests were analyzed using the SPSS software version 20.0 (SPSS, IBM Corporation, Armonk, NY, USA).

\section{Results}

Anthropometric variables of the experimental group were measured before and after the 12-week strength program and are presented in Table 1 . As shown by $P$-values, no significant differences were observed in all anthropometric parameters evaluated, noting that 12 weeks of strength training are not enough to modify body anthropometric components.

However, the physical capacity results indicate differences and enhanced cognitive outcomes can be seen in Table 2.
Table 2 depicts the results of the flexibility, scores of ULS and LLS, as well as the cognitive capacities (MoCA) obtained before and after the 12-week exercise intervention. The strength training group showed significant increases in the average upper body strength ( $58 \%$ with $P=0.01)$, lower body strength $(68 \%$ with $P=0.01)$, and cognitive capacity ( $19 \%$ with $P=0.01$ ). The relationship between the cognitive performance capacity and flexibility and strength is indicated in Table 3. Finally, Table 3 shows the correlation (inter-dependence) indexes between physical abilities and cognitive capacities of elderly women after 12 weeks of the described strength training program.

\section{Discussion}

The purpose this study was to verify the effect of a 12-week strength training program on cognition capacities of elderly women. The flexibility, ULS, LLS, and MoCA had statistical differences after the strength exercise program. Also, there was an association from MoCA to LLS.

Disabilities, dynapenia, and articular malfunction are issues of main concern in an aging population. Motor dysfunctions have been postulated as the major factors leading to the decline of autonomy capacity and quality of life in elderly populations worldwide. ${ }^{23-25}$ According to Davis et al, ${ }^{26}$ regular exercise helps to reduce the health care costs with an elderly population. Most of the exercise protocols currently recommended for aging subjects prioritizes the increase of strength capacity as the key factor for a healthy life, based on the putative hormone rebalance achieved by strength training. ${ }^{27}$

Although no significant differences were observed in the pre-/postanalysis of the anthropometric parameters (Table 1), these results suggest that the intervention time may be insufficient or have no effect on these parameters. However, flexibility results were significantly improved after 12 weeks of the described strength training (Table 2). These findings reinforce the importance of strength training protocols as nonpharmacological strategies in the prevention

Table I Anthropometric variables of elderly women before and after a I2-week strength training program

\begin{tabular}{|c|c|c|c|c|c|}
\hline \multirow[t]{3}{*}{ Variables } & \multicolumn{2}{|c|}{ Control group $(n=8)$} & \multicolumn{2}{|c|}{ Strength group $(n=29)$} & \multirow[t]{3}{*}{$\boldsymbol{F}$} \\
\hline & Pretest & Posttest & Pretest & Posttest & \\
\hline & $(X \pm S D)$ & $(X \pm S D)$ & $(X \pm S D)$ & $(X \pm S D)$ & \\
\hline Weight (kg) & $63.45 \pm 3.46$ & $63.91 \pm 4.82$ & $66.96 \pm 7.67$ & $66.43 \pm 8.32$ & 0.43 \\
\hline Height (m) & $1.50 \pm 0.05$ & $1.50 \pm 0.05$ & $1.55 \pm 0.1 \mathrm{I}$ & $1.55 \pm 0.13$ & 0.61 \\
\hline $\mathrm{BMI}\left(\mathrm{kg} / \mathrm{m}^{2}\right)$ & $27.89 \pm 1.11$ & $27.93 \pm 1.51$ & $27.56 \pm 4.59$ & $27.35 \pm 4.86$ & 0.77 \\
\hline WC (cm) & $87.14 \pm 2.47$ & $87.92 \pm 3.16$ & $86.72 \pm 9.54$ & $86.59 \pm 8.73$ & 1.42 \\
\hline
\end{tabular}

Abbreviations: ANOVA, analysis of variance; BMI, body mass index; CG, control group; SD, standard deviation; SG, strength group; WC, waist circumference; $X$, mean. 
Table 2 Flexibility test results, scores of ULS and LLS, and cognitive capacities (MoCA) of elderly women before and after a I2-week strength training program

\begin{tabular}{|c|c|c|c|c|c|}
\hline \multirow[t]{2}{*}{ Variables } & \multicolumn{2}{|c|}{ Control group $(n=8)$} & \multicolumn{2}{|c|}{ Strength group $(n=29)$} & \multirow[t]{2}{*}{$\boldsymbol{F}$} \\
\hline & $\begin{array}{l}\text { Pretest } \\
(X \pm S D)\end{array}$ & $\begin{array}{l}\text { Posttest } \\
(X \pm \text { SD) }\end{array}$ & $\begin{array}{l}\text { Pretest } \\
(X \pm \text { SD })\end{array}$ & $\begin{array}{l}\text { Posttest } \\
(X \pm S D)\end{array}$ & \\
\hline Flexibility (cm) & $14.28 \pm 1.25$ & $14.48 \pm 2.22$ & $14.24 \pm 2.18$ & $18.38 \pm 5.96^{\mathrm{a}, \mathrm{b}}$ & $14.25^{*}$ \\
\hline ULS (rep) & $12.14 \pm 2.47$ & $12.03 \pm 2.76$ & $12.52 \pm 3.03$ & $19.83 \pm 4.59^{a, b}$ & $26.58^{*}$ \\
\hline LLS (rep) & $16.57 \pm 2.69$ & $16.45 \pm 2.87$ & $16.03 \pm 2.78$ & $27.00 \pm 5.04^{\mathrm{a}, \mathrm{b}}$ & $48.73^{*}$ \\
\hline MoCA (points) & $14.28 \pm 4.02$ & $14.13 \pm 3.98$ & $16.55 \pm 4.24$ & $19.76 \pm 4.24^{\mathrm{a}, \mathrm{b}}$ & $3.02 *$ \\
\hline
\end{tabular}

Notes: *(Two-way) ANOVA with $P<0.05$. a Difference of the pre- and posttest in the SG. 'Difference between posttest in the CG with the posttest SG.

Abbreviations: ANOVA, analysis of variance; CG, control group; LLS, lower limb strength; MoCA, Montreal Cognitive Assessment; rep, repetitions; SD, standard deviation; SG, strength group; ULS, upper limb strength; $X$, mean.

of motor disabilities in the elderly ${ }^{28}$ Increased flexibility with strength training is showed as an indirect effect post exercise program. However, the exact mechanisms responsible for increase flexibility after strength training have not yet been establish in the literature. ${ }^{29}$

In agreement with the present finding reported in Table 2, Seco et $\mathrm{al}^{30}$ found positive results for the physical strength ability $(P=0.0001)$ as well as in the flexibility component ( $P=0.001$, while flexibility was maintained after 3 months of detraining. The results of the present study also demonstrated improvements in flexibility scores after the strength training intervention $(P=0.01)$.

After 12 weeks, the strength training intervention increased ULS by $58 \%$, whereas LLS showed an increase of $68 \%$ (Table 2). According to Radaelli et al, ${ }^{31}$ the "perfect" introductory strength training protocol for elderly women is still not described. These authors found a significant positive response after 6 weeks, when strength training sessions with frequency of two times per week also improved LLS (tested as $1 \mathrm{RM} ; P \leq 0.05)$. However, no substantial differences were observed when checking strength parameters after 12 weeks of the same protocol. ${ }^{31}$

Interesting results about the motor-cognition benefits obtained by strength training were also described by Vaughan et al..$^{32}$ The authors found out that different types

Table 3 Association indexes between physical fitness variables and cognitive capacities of elderly women before and after a I2-week strength training program $(n=29)$

\begin{tabular}{ll}
\hline Variables & (Cognitive capacity) MoCA \\
\cline { 2 - 2 } & Odds ratio $(95 \% \mathrm{Cl})$ \\
\hline Flexibility $(\mathrm{cm})$ & $0.54(0.08-3.37)$ \\
ULS (rep) & $12.01(0.61-236.32)$ \\
LLS (rep) & $0.03 *(1.02-13.69)$ \\
\hline
\end{tabular}

Note: $* p<0.05$.

Abbreviations: $\mathrm{Cl}$, confidence interval; LLS, lower limb strength; MoCA, Montreal Cognitive Assessment; rep, repetitions; ULS, upper limb strength. of exercises applied for 16 weeks improved some cognitive performance scores and the expression of brain-derived neurological factors associated with neurogenesis. In the study by Kirk-Sanchez and McGough, ${ }^{7}$ strength training interventions showed positive effects on cognition, especially in the executive answers. Similar results were also observed by Chang et $\mathrm{l}^{133}$ who suggested acute effects of the strength training sessions on cognition of elderly women. ${ }^{34}$

Moreover, Babaei et $\mathrm{al}^{35}$ has assigned the exercise as an enhancer of brain-derived neurotrophic factor that progressively implies on cognitive performance and neuroplasticity of older subjects. Following regular exercise programs, neurotrophic signals are released in the bloodstream (both at the central and peripheral systems) and trigger cascade reactions that induce neuroprotective responses and limit neural apoptosis caused by oxidative stress. ${ }^{36}$ Cognitive impairment in older people was markedly linked to Alzheimer's occurrence. Accordingly, Rao et $\mathrm{al}^{37}$ suggest that by introducing strength training protocols to circumvent neurodegenerative diseases, both patient and health care costs could be positively affected.

Gorelick et $a l^{38}$ report that strength exercises promote vascularization (both chronic and acute) throughout the body, inhibit the atherosclerotic plaque formation and, thereby, also enhance essential nutrient supply to the brain. Therefore, regular resistance exercises represent a nonpharmacological intervention to bring vascular, cognitive, and neuro-motor benefits to the elderly population, even in relatively long periods after the end of the training program (detraining period). ${ }^{39}$ The neurobiological mechanisms involved in cognition acquisition by strength training have been exhaustively investigated in the last decades. Blood rheology changes, steroid hormone rebalances, increases in neurotransmitter levels, releases of neurotrophic factors (linked to neuroplasticity), and mitochondrial functions in neurons are some of the key events currently investigated. ${ }^{40}$ 
One of the limitations in the present study refers to the daily food intake by volunteers, even when previously investigating their eating habits by anamnesis or food frequency questionnaires. ${ }^{41}$ As shown by several authors, the regular intake of particular micronutrients, such as omega 3 fatty acids, antioxidants, and flavonoids, could improve cognitive capacities in a chronic exposure mode, and delay the identification of the initial symptoms of neurodegenerative diseases. ${ }^{42}$ On the other hand, low levels of such micronutrients in the subjects' diet could drastically limit the acquired cognitive benefits from the strength training protocol applied here. ${ }^{43}$ Further studies are necessary to elucidate the proper mechanisms and the close relationship between strength exercises and positive cognition responses in elderly population, especially regarding nutrition.

\section{Conclusion}

The present study showed that a strength training protocol applied for 12 weeks to elderly women increased balance, flexibility, strength of upper and lower limbs, and increased cognitive performance. Based on our results, we can recommend strength training programs for elderly women that aim for the improvement of general strength and cognitive performance (under professional supervision).

\section{Acknowledgments}

Tácito P Souza-Junior is supported by a CNPq fellowship \#216382/2014-9.

\section{Author contributions}

All authors contributed toward data analysis, drafting and revising the paper and agree to be accountable for all aspects of the work.

\section{Disclosure}

The authors report no conflicts of interest in this work.

\section{References}

1. Aartolahti E, Hartikainen S, Lonnroos E, Hakkinen A. Health and physical function predicting strength and balance training adoption: a community-based study among individuals aged 75 and older. $J$ Aging Phys Act. 2014;22(4):543-549.

2. Terpening Z, Lewis SJ, Yee B, Grunstein R, Hickie IB, Naismith SL. Association between Sleep-disordered breathing and neuropsychological performance in older adults with mild cognitive impairment. $J$ Alzheimers Dis. 2015;46(1):157-165.

3. Barnes DE, Mehling W, Wu E, et al. Preventing loss of independence through exercise (PLIE): a pilot clinical trial in older adults with dementia. PLoS One. 2015;10(2): 0113367.

4. Wu E, Barnes DE, Ackerman SL, Lee J, Chesney M, Mehling WE. Preventing Loss of Independence through Exercise (PLIE): qualitative analysis of a clinical trial in older adults with dementia. Aging Ment Health. 2015;19(4):353-362.
5. Carvalho A, Barbirato D, Araujo N, et al. Comparison of strength training, aerobic training, and additional physical therapy as supplementary treatments for Parkinson's disease: pilot study. Clin Interv Aging. 2015; 10:183-191.

6. Arnold P, Bautmans I. The influence of strength training on muscle activation in elderly persons: a systematic review and meta-analysis. Exp Gerontol. 2014;58:58-68.

7. Kirk-Sanchez NJ, McGough EL. Physical exercise and cognitive performance in the elderly: current perspectives. Clin Interv Aging. 2014;9: $51-62$.

8. McEwen BS, Gianaros PJ. Stress- and allostasis-induced brain plasticity. Annu Rev Med. 2011;62:431-445.

9. Cassilhas RC, Viana VA, Grassmann V, et al. The impact of resistance exercise on the cognitive function of the elderly. Med Sci Sports Exerc. 2007;39(8):1401-1407.

10. Fragala MS, Beyer KS, Jajtner AR, et al. Resistance exercise may improve spatial awareness and visual reaction in older adults. $J$ Strength Cond Res. 2014;28(8):2079-2087.

11. Mazzulla S, Schella A, Gabriele D, et al. Oxidation of human red blood cells by a free radical initiator: Effects on rheological properties. Clin Hemorheol Microcirc. 2015;60(4):375-388.

12. Jiménez A, De Paz JA. Application of the 1rm estimation formulas from the $\mathrm{rm}$ in bench press in a group of physically active middle-aged women. J Hum Sport Exerc. 2008;3(1):10-22.

13. Farinatti PT, Geraldes AA, Bottaro MF, Lima MV, Albuquerque RB, Fleck SJ. Effects of different resistance training frequencies on the muscle strength and functional performance of active women older than 60 years. J Strength Cond Res. 2013;27(8):2225-2234.

14. Arazi H, Ghiasi A, Afkhami M. Effects of different rest intervals between circuit resistance exercises on post-exercise blood pressure responses in normotensive young males. Asian J Sports Med. 2013;4(1):63-69.

15. Delmonico MJ, Ferrell RE, Meerasahib A, et al. Blood pressure response to strength training may be influenced by angiotensinogen A-20C and angiotensin II type I receptor A1166C genotypes in older men and women. J Am Geriatr Soc. 2005;53(2):204-210.

16. Gordon C, Chumlea W, Roche A, Lohman T, Roche A, Martorell R. Anthropometric Standardizing Reference Manual. Champaign, IL: Human Kinetics Books; 1988.

17. Marfell-Jones M, Stewart A, de Ridder J. International Society for the Advancement of Kinanthropometry. Lower Hutt, New Zealand: ISAK; 2012.

18. Rickli RC, Jones JC. Teste de Aptidão Física para Idosos. São Paulo: Manole; 2008

19. Nasreddine ZS, Phillips NA, Bedirian V, et al. The Montreal Cognitive Assessment, MoCA: a brief screening tool for mild cognitive impairment. J Am Geriatr Soc. 2005;53(4):695-699.

20. Whitney KA, Mossbarger B, Herman SM, Ibarra SL. Is the Montreal cognitive assessment superior to the mini-mental state examination in detecting subtle cognitive impairment among middle-aged outpatient U.S. Military veterans? Arch Clin Neuropsychol. 2012;27(7): 742-748.

21. Yu J, Li J, Huang X. The Beijing version of the Montreal Cognitive Assessment as a brief screening tool for mild cognitive impairment: a community-based study. BMC Psychiatry. 2012;12:156.

22. Freitas S, Simões MR, Martins C, Vilar M, Santana I. Estudos de adaptação do Montreal Cognitive Assessment (MoCA) para a população portuguesa. [Adaptation studies of the Montreal Cognitive Assessment (MoCA) to the Portuguese population]. Aval Psicol. 2010;9(3):345-357.

23. Apor P, Babai L. [Physical activity diminishes aging-related decline of physical and cognitive performance]. Orv Hetil. 2014;155(21):817-821. Hungarian.

24. Judd DL, Thomas AC, Dayton MR, Stevens-Lapsley JE. Strength and functional deficits in individuals with hip osteoarthritis compared to healthy, older adults. Disabil Rehabil. 2014;36(4):307-312.

25. Montero-Fernandez N, Serra-Rexach JA. Role of exercise on sarcopenia in the elderly. Eur J Phys Rehabil Med. 2013;49(1):131-143. 
26. Davis JC, Bryan S, Marra CA, et al. An economic evaluation of resistance training and aerobic training versus balance and toning exercises in older adults with mild cognitive impairment. PLoS One. 2013;8(5): e63031.

27. Maggio M, Lauretani F, De Vita F, et al. Multiple hormonal dysregulation as determinant of low physical performance and mobility in older persons. Curr Pharm Des. 2014;20(19):3119-3148.

28. Emilio EJ, Hita-Contreras F, Jimenez-Lara PM, Latorre-Roman P, Martinez-Amat A. The association of flexibility, balance, and lumbar strength with balance ability: risk of falls in older adults. J Sports Sci Med. 2014;13(2):349-357.

29. Carneiro NH, Ribeiro AS, Nascimento MA, et al. Effects of different resistance training frequencies on flexibility in older women. Clin Interv Aging. 2015;10:531-538.

30. Seco J, Abecia LC, Echevarria E, et al. A long-term physical activity training program increases strength and flexibility, and improves balance in older adults. Rehabil Nurs. 2013;38(1):37-47.

31. Radaelli R, Wilhelm EN, Botton CE, et al. Effects of single vs. multipleset short-term strength training in elderly women. Age (Dordrecht, Netherlands). 2014;36(6):9720.

32. Vaughan S, Wallis M, Polit D, Steele M, Shum D, Morris N. The effects of multimodal exercise on cognitive and physical functioning and brain-derived neurotrophic factor in older women: a randomised controlled trial. Age Ageing. 2014;43(5):623-629.

33. Chang YK, Pan CY, Chen FT, Tsai CL, Huang CC. Effect of resistanceexercise training on cognitive function in healthy older adults: a review. J Aging Phys Act. 2012;20(4):497-517.

34. Chang YK, Tsai CL, Huang CC, Wang CC, Chu IH. Effects of acute resistance exercise on cognition in late middle-aged adults: general or specific cognitive improvement? J Sci Med Sport. 2014;17(1):51-55.
35. Babaei P, Azali Alamdari K, Soltani Tehrani B, Damirchi A. Effect of six weeks of endurance exercise and following detraining on serum brain derived neurotrophic factor and memory performance in middle aged males with metabolic syndrome. J Sports Med Phys Fitness. 2013; 53(4):437-443.

36. Knaepen K, Goekint M, Heyman EM, Meeusen R. Neuroplasticity exercise-induced response of peripheral brain-derived neurotrophic factor: a systematic review of experimental studies in human subjects. Sports Med (Auckland, NZ). 2010;40(9):765-801.

37. Rao AK, Chou A, Bursley B, Smulofsky J, Jezequel J. Systematic review of the effects of exercise on activities of daily living in people with Alzheimer's disease. Am J Occup Ther. 2014;68(1):50-56.

38. Gorelick PB, Scuteri A, Black SE, et al. Vascular contributions to cognitive impairment and dementia: a statement for healthcare professionals from the American Heart Association/American Stroke Association. Stroke. 2011;42(9):2672-2713.

39. Berryman N, Bherer L, Nadeau S, et al. Multiple roads lead to Rome: combined high-intensity aerobic and strength training vs. gross motor activities leads to equivalent improvement in executive functions in a cohort of healthy older adults. Age (Dordrecht, Netherlands). 2014;36(5):9710.

40. Deslandes A. The biological clock keeps ticking, but exercise may turn it back. Arg Neuropsiquiatr. 2013;71(2):113-118.

41. Meng X, Kerr DA, Zhu K, et al. Under-reporting of energy intake in elderly Australian women is associated with a higher body mass index. J Nutr Health Aging. 2013;17(2):112-118.

42. Wu Z, Yu J, Zhu A, Nakanishi H. Nutrients, Microglia Aging, and Brain Aging. Oxidative medicine and cellular longevity. 2016;2016: 7498528.

43. Meeusen R. Exercise, nutrition and the brain. Sports Med (Auckland, NZ). 2014;44 Suppl 1:S47-S56
Clinical Interventions in Aging

\section{Publish your work in this journal}

Clinical Interventions in Aging is an international, peer-reviewed journal focusing on evidence-based reports on the value or lack thereof of treatments intended to prevent or delay the onset of maladaptive correlates of aging in human beings. This journal is indexed on PubMed Central, MedLine,

\section{Dovepress}

CAS, Scopus and the Elsevier Bibliographic databases. The manuscript management system is completely online and includes a very quick and fair peer-review system, which is all easy to use. Visit http://www.dovepress. com/testimonials.php to read real quotes from published authors. 